\title{
Effects of oral supplementation with FOS and GOS prebiotics in women with adult acne: the "S.O. Sweet" study: a proof-of-concept pilot trial
}

This article was published in the following Dove Press journal: Clinical, Cosmetic and Investigational Dermatology

\author{
Federica Dall'Oglio' \\ Massimo Milani² \\ Giuseppe Micali' \\ 'Dermatology Clinic, University \\ of Catania, Catania, Italy; ${ }^{2}$ Medical \\ Department, Cantabria Labs Difa \\ Cooper, Caronno Pertusella (VA), Italy
}

Correspondence: Massimo Milani Cantabria Labs Difa Cooper, Via Milano 160, Caronno Pertusella, Varese, Italy Tel +39029659031

Email massimo.milani@difacooper.com
Background: We evaluated the effects of 3-month prebiotic oral supplementation with fructooligosaccharides (FOS) and galacto-oligosaccharides (GOS) on glucose and lipid metabolic parameters in women with adult acne (female adult acne).

Methods: Twelve women, mean age 35 years, with mild to moderate acne were enrolled. Exclusion criteria were severe acne, body mass index $(\mathrm{BMI})>25$, history of diabetes mellitus, polycystic ovary syndrome, regular intake of prebiotics or probiotics, and history of inflammatory intestinal diseases. At baseline visit (T0), at month 1 (T1), and at month 3 (T2) fasting glucose, blood insulin, glycated hemoglobin (HbAlc), C-peptide, triglycerides, total cholesterol levels, and BMI were measured. Subjects were treated with a food supplement containing FOS (100 $\mathrm{mg}$ ) and GOS (500 mg), one sachet daily, for 3 months. Subjects were instructed to follow their regular diet, and no dietary restrictions were suggested.

Results: At baseline, the BMI, mean $\pm \mathrm{SD}$, was $23 \pm 0.7$. No modification of BMI was observed during the study. At baseline, fasting blood glucose levels were $92 \pm 7 \mathrm{mg} / \mathrm{dL}$. A significant $(P=0.02)$ reduction was observed at month $1(86 \pm 5 \mathrm{mg} / \mathrm{dL})$ and at month $3(85 \pm 7 \mathrm{mg} / \mathrm{dL})$ $(-10 \%)$. Total cholesterol levels were reduced significantly $(P=0.018)$ from $184 \pm 19$ to $161 \pm 10$ $\mathrm{mg} / \mathrm{dL}(-13 \%)$ at the end of the study. Triglycerides at baseline were $51 \mathrm{mg} / \mathrm{dL}$ and were reduced to $46 \mathrm{mg} / \mathrm{dL}(P=0.05)$. Insulin and $\mathrm{C}$-peptide plasma levels showed a nonsignificant reduction trend from baseline to the end of the study. In subjects with baseline insulin level $>6 \mu \mathrm{UI} / \mathrm{mL}$ $(n=6)$ the FOS/GOS supplementation induced a significant $(P=0.03)$ reduction from 7.8 to 4.3 $\mu \mathrm{UI} / \mathrm{mL}$ at day $90(-45 \%)$. C-peptide was reduced from 2.1 to $1.6 \mathrm{ng} / \mathrm{mL}$ (month 3 ). $\mathrm{HbA} 1 \mathrm{c}$ at baseline was $35 \mathrm{mg} / \mathrm{dL}$ and $32 \mathrm{mg} / \mathrm{dL}$ at the end of the study (NS).

Conclusion: In adult female acne, supplementation with prebiotic FOS and GOS was associated with positive effects on glycemic and lipid metabolic parameters.

Keywords: adult female acne, glycemic index, diet, prebiotics, fructo-oligosaccharides, galacto-oligosaccharides

\section{Introduction}

Adult female acne (AFA) is a skin disease of increasing incidence ${ }^{1}$ that may affect up to $50 \%$ of women above 25 years of age. ${ }^{2}$ Its pathogenesis is unknown. Recent epidemiologic data demonstrated that AFA may be associated with metabolic syndrome and high glycemic index ${ }^{3}$ caused by elevated blood level of IGF-1, which may induce comedogenesis and inflammation of sebaceous glands. ${ }^{4}$ Some epidemiological data have shown that a high-carbohydrate ( $>55 \%$ of energy from carbohydrate) and highfat diet worsens acne. ${ }^{5}$ Aizawa and Niimura ${ }^{6}$ demonstrated that adult women with acne presented mild insulin resistance during oral glucose tolerance test. Chronic and 
acute hyperinsulinemia upregulates the production of IGF-1, which is a potent mitogen stimulating cellular growth at the follicle level as well. ${ }^{7}$ In animal models, overexpression of IGF-1 induces hyperkeratosis and epidermal hyperplasia. ${ }^{8}$ Furthermore, IGF-1 increases the production of sebum. ${ }^{9}$ IGF-1 serum levels are elevated in women with postadolescent acne..$^{10}$ Both insulin and IGF-1 stimulate the production of androgens in ovarian and testicular tissues. ${ }^{11,12}$ These data support the hypothesis that the endocrine cascade induced by hyperinsulinemia enhances sebum production and acne development. Modification of intestinal microbiota has been implicated in insulin resistance. ${ }^{13}$ Larsen et al ${ }^{14}$ have shown that gut microbiota in type 2 diabetic subjects differs from nondiabetic adults. In obese subjects, therapeutic modification of intestinal microbiota is associated with an improvement of insulin sensitivity. ${ }^{15}$ Fructo-oligosaccharides (FOS) and galacto-oligosaccharides (GOS) are prebiotic substances able to improve intestinal microbiota and oral supplementation with both increases the amount of intestinal Bifidumbacterium spp. and Lactobacillus spp. ${ }^{16}$ Experimental data show that oral supplementation with FOS and GOS could have positive effect on glucose metabolism in healthy nondiabetic individuals, thereby reducing the glycemic diet load effects. ${ }^{17}$ So far, no data regarding the effects of FOS/ GOS dietary supplementation on glycemic parameters in subjects with AFA are available.

\section{Study aim}

To evaluate, in a pilot study, the effects of prebiotic oral supplementation with FOS and GOS on glucose and lipid metabolic parameters in women with adult acne.

\section{Subjects and methods Study design}

The study ("S.O. Sweet trial") was designed as open prospective proof-of-concept trial. The clinical setting was the acne outpatient service at the Dermatology Clinic of Catania University. The study took place from July 2017 to December 2017. The institutional review board of the Catania University approved the study protocol. The trial was conducted according to Good Clinical Practice Guidelines and Helsinki Declaration (update 2014). ${ }^{18}$

\section{Subjects}

Eligible subjects included women aged $\geq 25$ years with mild to moderate acne. A total of 12 women, mean age 35 years, were included in the study after their written informed consent. Exclusion criteria were severe acne, body mass index (BMI)
$>25$, smoking habits, use of oral contraceptives, history of diabetes mellitus, regular intake of prebiotics or probiotics, and history of inflammatory intestinal diseases.

\section{Study outcomes}

At baseline visit (T0), at day 30 (month 1), and at day 90 (month 2), fasting glucose, blood insulin, glycated hemoglobin (HbA1c), C-peptide, triglycerides, total cholesterol levels, and BMI were measured. HbA1c levels were measured by low-pressure liquid chromatography. Serum C-peptide levels were measured by radioimmunoassay using commercial kits (Diagnostic Systems Laboratories Inc, Webster, TX, USA).

\section{Intervention}

Subjects were treated with a food supplement containing FOS (100 mg) and GOS (500 mg), one sachet daily (Sebogard oral, Cantabria Labs Difa Cooper, Caronno Pertusella, Italy), for 3 consecutive months. Subjects were instructed to follow their regular diet, and no dietary restrictions were suggested.

\section{Statistical analysis}

Statistical analysis was performed using GraphPad Statistical Software (GraphPad Software, Inc., La Jolla, CA, USA). Continuous variables were expressed as mean $\pm \mathrm{SD}$. The primary outcomes of the study were to evaluate the evolution of glycemic and lipidic parameters. For inferential statistical analysis, we used the ANOVA multiple comparison test and the paired Student's $t$-test. In view of the proof-of-concept nature of the present trial, a formal sample size calculation was not performed. We decided to enroll at least ten evaluable subjects.

\section{Results}

All enrolled women completed the 3-month study period. At baseline the $\mathrm{BMI}$, mean $\pm \mathrm{SD}$, was $23 \pm 0.7$. No modification of BMI was observed during the study duration (BMI $23 \pm 6$ at month 3). At baseline, fasting blood glucose levels were $92 \pm 7 \mathrm{mg} / \mathrm{dL}$. A progressive and significant ( $P=0.02$; ANOVA) reduction was observed at month $1(86 \pm 5 \mathrm{mg} / \mathrm{dL})$ and at month $3(85 \pm 7 \mathrm{mg} / \mathrm{dL})(-10 \%)$ (Figure 1). Total cholesterol levels were reduced significantly $(P=0.05)$ from $184 \pm 19$ to $161 \pm 10 \mathrm{mg} / \mathrm{dL}(-13 \%)$ at the end of the study (Figure 2$)$. Triglycerides at baseline were $51 \mathrm{mg} / \mathrm{dL}$ and were reduced to $46 \mathrm{mg} / \mathrm{dL}(P=0.05)$. Insulin and $\mathrm{C}$-peptide plasma levels showed a nonsignificant reduction trend from baseline to the end of the study. In subjects with baseline insulin level $>6 \mu \mathrm{UI} / \mathrm{mL}(\mathrm{n}=6)$ the FOS/GOS supplementation induced a significant $(P=0.03)$ reduction from 7.8 to $4.3 \mu \mathrm{UI} / \mathrm{mL}$ at 


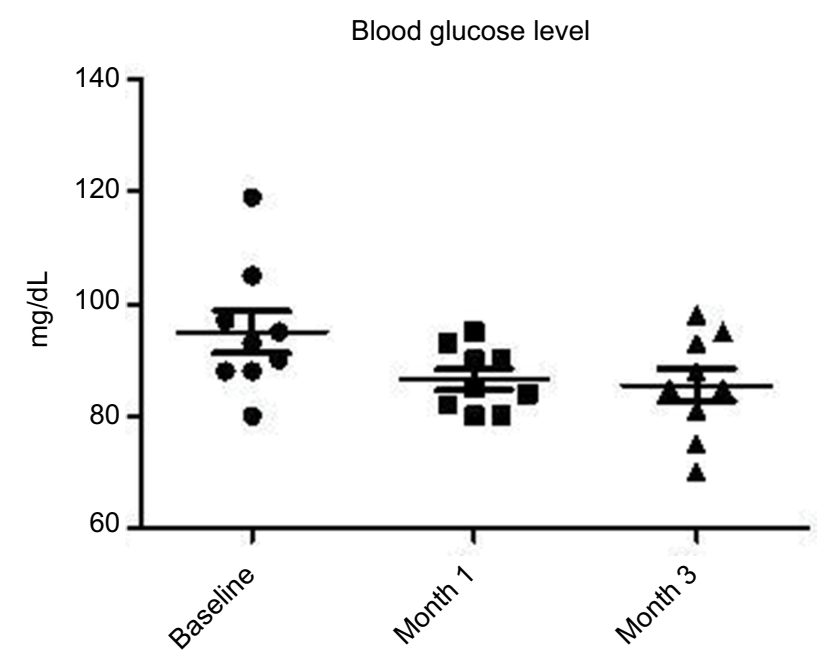

Figure I Evolution of glucose serum levels at baseline and during I and 3 months of FOS/GOS dietary supplementation ( $P=0.022$; ANOVA).

Abbreviations: ANOVA, analysis of variance; FOS/GOS, fructo-oligosaccharides/ galacto-oligosaccharides.

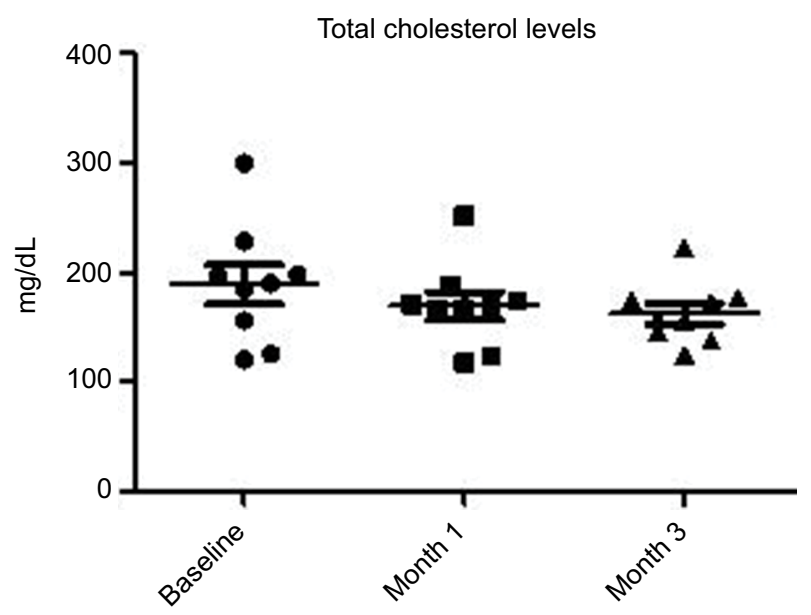

Figure 2 Evolution of total cholesterol serum levels at baseline and during FOS/ GOS dietary supplementation from baseline and after I and 3 months $(P=0.018$; ANOVA).

Abbreviations: ANOVA, analysis of variance FOS/GOS, fructo-oligosaccharides/ galacto-oligosaccharides.

day 90 (-45\%) (Figure 3). C-peptide was reduced from 2.1 to $1.6 \mathrm{ng} / \mathrm{mL}$ at day $90 . \mathrm{HbA} 1 \mathrm{c}$ at baseline was $35 \mathrm{mg} / \mathrm{dL}$, and it was $32 \mathrm{mg} / \mathrm{dL}$ (difference not significant) at the end of the study. The product was very well tolerated. No serious adverse events were reported during the entire study duration. Even if it was not an endpoint of this trial, a general improvement of acne lesion count was also observed in comparison with baseline condition.

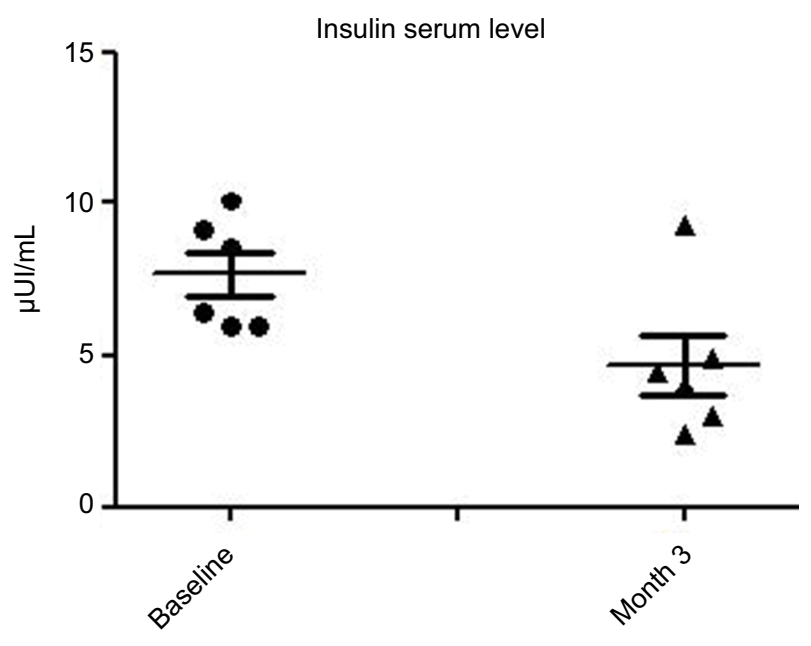

Figure 3 Evolution of insulin serum level (subset of subjects with baseline insulin levels $>6 \mu \mathrm{UI} / \mathrm{mL})(P=0.03$; paired $t$-test $)$.

\section{Discussion}

Acne is a common and complex skin disease that affects individuals of all ages. ${ }^{19}$ Acne is most common in teenagers, but acne can be observed in $54 \%$ of adult females and $40 \%$ of adult males, and its prevalence does not decrease substantially with age. ${ }^{20} \mathrm{AFA}$ is a skin disease of increasing incidence that may affect up to $50 \%$ of women above 25 years of age. ${ }^{1,2}$ AFA is classically distinguished into three subtypes: ${ }^{21}$ "persistent acne" (adolescent acne that is persistent after adolescence), "late onset acne" (characteristically starts after 25 years of age with no previous history of acne), and "recurrent acne" (distinguished by the disappearance of acne for years and by its recurrence). Factors involved in the pathogenesis of adult acne include genetic factors, hypercolonization of resistant strains of Propionibacterium acnes, hyperandrogenism with or without polycystic ovarian syndrome, ${ }^{1}$ increased serum levels of insulin and IGF- $1,{ }^{22}$ and the use of comedogenic substances. ${ }^{23}$ Also, stress and smoking ${ }^{24}$ seem to be associated with AFA, even if some epidemiological data do not support this link. ${ }^{25}$ Recent evidences show that glycemic load and glycemic index of whole diet may participate in the pathogenesis of AFA by increasing serum levels of insulin that in turn may increase the blood levels of IGF-1 and adiponectin responsible for comedogenesis and inflammation. ${ }^{26}$ In a trial conducted by Smith et al, ${ }^{27}$ a low glycemic load diet significantly reduced acne lesion count improving insulin sensitivity. However, in this trial there was a concomitant weight loss in the group assigned to low glycemic load diet, which could have interfered with the net clinical outcome. 
An alteration of intestinal microbiota has also been claimed in one study, with $66 \%$ of 57 patients affected by AFA showing positive reactivity to stool-isolated coliforms compared to none of the control patients without active skin disease. ${ }^{28}$ Finally, high fat and sugar diet with low fibers may lead to gut motility alterations, loss of normal microbial biofilm (Bifidobacterium in particular), and increased intestinal permeability (loss of intestinal barrier). ${ }^{29}$ The latter may cause efflux of lipopolysaccharide endotoxins into systemic circulation, promoting low-grade inflammation, oxidative stress, release of substance $P$, and increased permeability of IGF-1, which in turn cause insulin resistance, hyperinsulinemia, type 2 diabetes, and likely onset of acne. ${ }^{30}$ Finally, oral nutritional supplementation with prebiotics like FOS and GOS has been demonstrated to increase stool colony counts of Bifidobacteria and Lactobacilli, contributing to maintain efficient intestinal mucosal barrier. ${ }^{31}$ Prebiotics could improve insulin sensitivity, thus controlling the role of high glycemic diets in acne exacerbation. ${ }^{32}$ The results of our study support the hypothesis that dietary supplementation with some prebiotics, in particular FOS and GOS, may improve some blood parameters of sugar and lipid metabolism in women with AFA. Some limitations should be taken in account while evaluating our results. This was an open, uncontrolled trial performed in 12 subjects. The sample size was small. However, we wanted to enroll subjects with specific inclusion and exclusion criteria to reduce confounding factors (no diabetes, no polycystic ovarian syndrome, etc), and these aspects have substantially reduced the eligible population. Therefore, our study should be considered as a pilot trial.

\section{Conclusion}

In AFA, oral supplementation with prebiotic FOS and GOS was associated with positive effects on glycemic and lipid metabolism parameters. Further controlled comparative studies are warranted to better evaluate these effects in a larger population of AFA subjects.

\section{Author contributions}

All authors contributed toward data analysis, drafting and critically revising the paper and agree to be accountable for all aspects of the work.

\section{Disclosure}

FDo and GM have disclosed that they have no significant relationships with or financial interests in any commercial companies related to this study or article. MM is an employee of Cantabria Labs Difa Cooper. MM reports grants from Difa
Cooper, during the conduct of the study, and grants from Difa Cooper, outside the submitted work.

\section{References}

1. Dréno B, Layton A, Zouboulis CC, et al. Adult female acne: a new paradigm. J Eur Acad Dermatol Venereol. 2013;27(9):1063-1070.

2. Zeichner JA, Baldwin HE, Cook-Bolden FE, Eichenfield LF, FallonFriedlander S, Rodriguez DA. Emerging Issues in Adult Female Acne. J Clin Aesthet Dermatol. 2017;10(1):37-46.

3. KaymakY, Adisen E, Ilter N, Bideci A, Gurler D, Celik B. Dietary glycemic index and glucose, insulin, insulin-like growth factor-I, insulin-like growth factor binding protein 3 , and leptin levels in patients with acne. J Am Acad Dermatol. 2007;57(5):819-823.

4. Kurokawa I, Danby FW, Ju Q, et al. New developments in our understanding of acne pathogenesis and treatment. Exp Dermatol. 2009;18(10):821-832.

5. Bowe WP, Joshi SS, Shalita AR. Diet and acne. J Am Acad Dermatol. 2010;63(1):124-141.

6. Aizawa H, Niimura M. Mild insulin resistance during oral glucose tolerance test (OGTT) in women with acne. J Dermatol. 1996;23(8):526-529.

7. Deplewski D, Rosenfield RL. Growth hormone and insulin-like growth factors have different effects on sebaceous cell growth and differentiation. Endocrinology. 1999;140(9):4089-4094.

8. Bol DK, Kiguchi K, Gimenez-Conti I, Rupp T, Digiovanni J. Overexpression of insulin-like growth factor-1 induces hyperplasia, dermal abnormalities, and spontaneous tumor formation in transgenic mice. Oncogene. 1997;14(14):1725-1734.

9. Smith TM, Gilliland K, Clawson GA, Thiboutot D. IGF-1 induces SREBP-1 expression and lipogenesis in SEB-1 sebocytes via activation of the phosphoinositide 3-kinase/Akt pathway. J Invest Dermatol. 2008;128(5):1286-1293.

10. Balta I, Ekiz O, Ozuguz $\mathrm{P}$, et al. Insulin resistance in patients with postadolescent acne. Int J Dermatol. 2015;54(6):662-666.

11. Barbieri RL, Smith S, Ryan KJ. The role of hyperinsulinemia in the pathogenesis of ovarian hyperandrogenism. Fertil Steril. 1988;50(2): 197-212.

12. Bebakar WM, Honour JW, Foster D, Liu YL, Jacobs HS. Regulation of testicular function by insulin and transforming growth factor-beta. Steroids. 1990;55(6):266-270.

13. Dumas ME, Barton RH, Toye A, et al. Metabolic profiling reveals a contribution of gut microbiota to fatty liver phenotype in insulin-resistant mice. Proc Natl Acad Sci U S A. 2006;103(33):12511-12516.

14. Larsen N, Vogensen FK, van den Berg FW, et al. Gut microbiota in human adults with type 2 diabetes differs from non-diabetic adults. PLoS One. 2010;5(2):e9085.

15. Vrieze A, van Nood E, Holleman F, et al. Transfer of intestinal microbiota from lean donors increases insulin sensitivity in individuals with metabolic syndrome. Gastroenterology. 2012;143(4):913-916.

16. Collins MD, Gibson GR. Probiotics, prebiotics, and synbiotics: approaches for modulating the microbial ecology of the gut. Am J Clin Nutr. 1999;69(5):1052s-1057.

17. Costa GT, Guimarães SB, Sampaio HA. Fructo-oligosaccharide effects on blood glucose: an overview. Acta Cir Bras. 2012;27(3):279-282.

18. General Assembly of the World Medical Association. World Medical Association Declaration of Helsinki: ethical principles for medical research involving human subjects. J Am Coll Dent. 2014;81(3): 14 .

19. Williams HC, Dellavalle RP, Garner S. Acne vulgaris. The Lancet. 2012;379(9813):361-372.

20. Bergfeld WF. A lifetime of healthy skin: implications for women. Int $J$ Fertil Womens Med. 1999;44(2):83-95.

21. Ramos-E-Silva M, Ramos-E-Silva S, Carneiro S. Acne in women. $\mathrm{Br}$ J Dermatol. 2015;172 Suppl 1:20-26.

22. Melnik BC, Schmitz G. Role of insulin, insulin-like growth factor-1, hyperglycaemic food and milk consumption in the pathogenesis of acne vulgaris. Exp Dermatol. 2009;18(10):833-841. 
23. White GM. Recent findings in the epidemiologic evidence, classification, and subtypes of acne vulgaris. J Am Acad Dermatol. 1998;39(2 Pt 3): S34-S37.

24. Yang YS, Lim HK, Hong KK, et al. Cigarette smoke-induced interleukin-1 alpha may be involved in the pathogenesis of adult acne. Ann Dermatol. 2014;26(1):11-16.

25. Youn SW. The role of facial sebum secretion in acne pathogenesis: facts and controversies. Clin Dermatol. 2010;28(1):8-11.

26. Cappel M, Mauger D, Thiboutot D. Correlation between serum levels of insulin-like growth factor 1, dehydroepiandrosterone sulfate, and dihydrotestosterone and acne lesion counts in adult women. Arch Dermatol. 2005;141(3):333-338.

27. Smith RN, Mann NJ, Braue A, Mäkeläinen H, Varigos GA. A lowglycemic-load diet improves symptoms in acne vulgaris patients: a randomized controlled trial. Am J Clin Nutr. 2007;86(1):107-115.
28. Bowe WP, Logan AC. Acne vulgaris, probiotics and the gut-brain-skin axis - back to the future? Gut Pathog. 2011;3(1):1.

29. Tilg H, Kaser A. Gut microbiome, obesity, and metabolic dysfunction. J Clin Invest. 2011;121(6):2126-2132.

30. Melnik BC. Linking diet to acne metabolomics, inflammation, and comedogenesis: an update. Clin Cosmet Investig Dermatol. 2015; $8: 371$.

31. Haarman M, Knol J. Quantitative real-time PCR assays to identify and quantify fecal Bifidobacterium species in infants receiving a prebiotic infant formula. Appl Environ Microbiol. 2005;71(5): 2318-2324.

32. Kumar S, Mahajan BB, Kamra N. Future perspective of probiotics in dermatology: an old wine in new bottle. Dermatol Online J. 2014;20(9):13030/qt8br333fc.
Clinical, Cosmetic and Investigational Dermatology

\section{Publish your work in this journal}

Clinical, Cosmetic and Investigational Dermatology is an international, peer-reviewed, open access, online journal that focuses on the latest clinical and experimental research in all aspects of skin disease and cosmetic interventions. This journal is included on PubMed. The manuscript management system is completely online

\section{Dovepress}

and includes a very quick and fair peer-review system, which is all easy to use. Visit http://www.dovepress.com/testimonials.php to read real quotes from published authors 